\title{
Dr. James Arthur Sharpe
}

Dr. James Arthur Sharpe died unexpectedly and peacefully at age 72 on November 12, 2013. Jim was a world-renowned neurologist and neuroophthalmologist who was known for his great and inquisitive mind.

Jim was born and raised in Brantford Ontario. He was the valedictorian of his graduating medical class at the University of Western Ontario. Jim began his illustrious neurology and neuroophthalmology career in 1968 when he started his neurology residency at the University of Toronto. This was followed by a neurophysiology fellowship at St. Michael's Hospital in Toronto. Subsequent to that, he did three neuroophthalmology fellowships. The first one was done at Bascom Palmer in Miami with Drs. Bob Daroff, Joel Glaser, and Noble David. This was followed by a second neuro-ophthalmology fellowship at the University of California, San Francisco with Dr. Bill Hoyt. For his third fellowship, he went abroad to train with Dr. Michael Sanders at Queen Square in London, England. In 1974, Jim joined the Division of Neurology at the University of Toronto and became the Director of the Neuro-Ophthalmology Unit at the Toronto Western Hospital. In 1986, he became a Professor of Neurology, Ophthalmology and Vision Sciences, and Otolaryngology-Head and Neck Surgery and the Head of Neurology at the Toronto Western Hospital, a position he held for 10 years. Three years later, he became the Head of Neurology at the University of Toronto, and he served in this capacity for 13 years until 2002 .

Jim was also a prominent scientist and a giant in the field of eye movement research. He published seminal papers on a wide variety of topics that were truly groundbreaking. He was instrumental in advancing our field, and was recognized internationally as a pioneer. He served as the President of the North American Neuro-Ophthalmology Society, as well as the Editor-in-Chief of the Canadian Journal of Neurological Sciences. Of all the awards he was honoured to receive, the one that he was most proud of was the Distinguished Service Award, the highest award given by the North American Neuro-Ophthalmology Society.

Jim has mentored numerous neurology and ophthalmology residents, fellows, and students. Many of his trainees have in turn become expert clinicians and scientists, professors, and departmental chairs all over the world. Over the years, Jim continued to be a beloved mentor, a wonderful colleague, and a trusted friend to many of us. His kindness, thoughtfulness and great sense of humour are deeply appreciated by all who have had worked with him.

Jim's passion for his life's work continued well into his 72nd year. Outside his clinic and laboratory he was an enthusiastic reader, traveller, golfer, skier, sailor, and fisherman. Always an optimist, Jim purchased new state of the art skis this year while recovering from cancer surgery. Jim's passion for life and all it has to offer was an inspiration to all who knew him. He is survived and profoundly missed by his loving long-time partner Adrienne, three children Jason (wife Tanya), Peter (wife Erin) and Katie (partner Blake), former wife Evelyn Sharpe (nee Farr), and six grandchildren. He is missed by his many friends and colleagues around the world.

Agnes Wong

University of Toronto, Toronto, Ontario, Canada 